\title{
Challenges facing online research: Experiences from research concerning cyber-victimisation of people with disabilities
}

\author{
Zhraa A. Alhaboby, James Barnes, Hala Evans, \& Emma Short \\ University of Bedfordshire, Luton, United Kingdom
}

\begin{abstract}
The victimisation of people living with disabilities and chronic conditions is a documented phenomenon. It ranges from harassment incidents to disability hate crimes, and causes physical, mental and psychosocial consequences. The Internet has further reshaped this phenomenon which lead to "cyber-victimisation" experiences, with no less impact upon victims. This methodology paper focuses mainly on the challenges and implications of using online methods in a UK-based study exploring the impact of cyber-victimisation on people coping with disabilities and chronic conditions. Mixed-method design was adopted via an online-survey followed by in-depth interviewing of victims. Online recruitment was through victim-support groups, patient-support groups, and social media. Out of 80 organisations and charities approached, 51(63.8\%) gatekeepers helped to reach participants. Recruitment and data collection process was challenged by four overarching themes: 1) social identity in online support groups, 2) the role of online gatekeepers, 3) the contradictory role of social media, and 4) promoting inclusivity. These challenges were theorised from the perspective of the Social Identity Theory. Representing self as a victim and/or a disabled-person had its implications on virtual groups' membership, social media use, gatekeepers' decisions and subsequent participation. Some identity aspects were highlighted as positive points to improve engagement with research. In conclusion, the Internet has aggravated the vulnerability of people with disabilities, but it also has a huge potential in researching sensitive topics with this group. Future research in the cyberspace should acknowledge the challenges of online identities of disabled victimised people, and focus on positive identity aspects to facilitate the research process and encourage collaborative participation at early stages of research.
\end{abstract}

Keywords: cyberstalking; cyberharrasment; disability hate crime; Social Identity Theory; online research; methodological challenges

\section{Introduction}

The Internet has become a part of everyday life which has influenced several aspects of healthcare and research (Walker, 2013; Wells \& Mitchell, 2014). Millions of people are affected by long term conditions (WHO, 2014), and millions living with physical or mental impairments qualify the legal definition of disability (EA, 2010b; ODI, 2014). Coping with these conditions requires adopting a specific lifestyle, social support, and/or taking medications. It is therefore demanding; physically, emotionally, intellectually and socially (Hinder \& Greenhalgh, 2012). The advancements in electronic communications have changed people's coping experiences with disabling conditions; individuals having long term conditions and disabilities go online for socialisation or health support (Didden et al., 2009; Fox \& Purcell, 2010; Merolli, Gray, \& Martin-Sanchez, 2013; ONS, 2014). Likewise, online 
methods in research have been introduced to improve health support for this group, for example online peer support to manage health was found to be beneficial and comparable to face-to-face support (Coulson, 2015; Lorig, Ritter, Laurent, \& Plant, 2006; McDermott \& While, 2013). Other health researchers utilised social media to recruit hard-to-reach populations (O'connor, Jackson, Goldsmith, \& Skirton, 2014). However, the use of the Internet in health research was rather ambitious, and despite the benefits of using new methods, the risk of online encounters was rarely reported (Merolli et al., 2013). This is especially important when considering vulnerable groups, such as the acknowledged risks facing people with intellectual disabilities (Buijs, Boot, Shugar, Fung, \& Bassett, 2016). Hence, there are gaps in reporting the use of online methods with "vulnerable groups".

In the research setting, vulnerability is a widely used term when considering ethical matters; it is a status given to participants who require special protection by researchers and ethics committees (Levine et al., 2004). It was first used to describe individuals aged 16 years or younger, people who do not have the mental capacity to consent according to the Mental Capacity Act (MCA, 2005), or in situations where unequal power relations are anticipated (BPS, 2010). Vulnerable groups' categories are being increasingly broader, with encouragements to include individuals having disabilities or long term life-threatening illnesses (Kipnis, 2001). It is to be noted that the conceptualisation of vulnerability by research ethics committees is problematic when it comes to people with disabilities (Gustafson \& Brunger, 2014). Defining vulnerability highly follows constructing disability under either the medical or the social models. The medical model focuses on the deficit, which is the impairment or the health condition that requires management, and hence people are labelled "disabled" and vulnerable due to the impairment itself (Forhan, 2009; Humpage, 2007). The social model separates the impairment from disability, and disability in this sense is created by the society towards people with impairments (Anastasiou \& Kauffman, 2013), hence people with impairments are made vulnerable by others (Emerson \& Roulstone, 2014). In this paper we acknowledge the notion of vulnerability under the social model as a source of discrimination and hostility against people with disabilities, but we also refer to the medical conditions due their impact on daily life.

To illustrate methodological issues in employing the Internet in research concerned with individuals having disabilities as a vulnerable group, this paper will focus on victimisation as a research area, and support the discussion with lessons learned from a UK-based study on cyber-victimisation impact. When applying the concept of victimisation in more general terms, this definition can imply a repeated negative behaviour or attention by an individual or a group towards the "victim" over a period of time (Kouwenberg, Rieffe, Theunissen, \& de Rooij, 2012). These experiences range from hostile incidents of harassment or bullying to a series of events such as stalking or disability hate crimes (Quarmby, 2011). People with long term conditions and disabilities were frequently victimised due to being "different" from others in cases of visible impairments (Horowitz et al., 2004), or because of adopting a lifestyle that differs from peers (Sentenac et al., 2011). The impact of offline victimisation on disabled people includes mental health consequences (Hugh-Jones \& Smith, 1999; Sheridan \& Grant, 2007), physical health complaints (Sentenac et al., 2013; Zinner, Conelea, Glew, Woods, \& Budman, 2012) and disruption in managing the health condition (Sentenac et al., 2011). On top of the documented discrimination against people with disabilities in offline context, electronic communications had extended physical environments to virtual ones, eliminated international borders and provided harassers with anonymity (Sheridan \& Grant, 2007), which lead to "cyber-victimisation" incidents.

Cases of cyber-victimisation are increasingly reported against people with disabilities, examples include cyberharrasment (Annerbäck, Sahlqvist, \& Wingren, 2014; Fridh, Lindström, \& Rosvall, 2015), cyberstalking (Sheridan \& Grant, 2007), cyberbullying (Yen et al., 2014), cyber-disability hate crimes (Alhaboby, al-Khateeb, Barnes, \& Short, 2016) or cyber sexual solicitation (Normand \& Sallafranque-St-Louis, 2016; Wells \& Mitchell, 2007). Despite using different terminologies, most of these offences share the criteria of being an anti-social behaviour by the "offender" towards the "victim" facilitated by electronic communications such as social media, email, chartrooms, online forums, instant messaging and other means (Maple, Short, \& Brown, 2011; Wells \& Mitchell, 2014). Cyber-victimisation and cyberharrasment are umbrella terms, while cyberstalking is further characterised by persistence and fixation (Sheridan \& Grant, 2007), and cyberbullying involves perceived power differences between the victim and the offender (Kowalski \& Fedina, 2011). Due to the variations in definitions and methods used, the prevalence of cyber-victimisation varies in the general population (Dreßing, Bailer, Anders, Wagner, \& Gallas, 2014) and also varies against people with disabilities, with a frequency reaching up to 41.5\% (Fridh et al., 2015). 
The use of technology in research on victimisation was through employing online surveys with victims of traditional abuse (Richardson et al., 2016), or cyber abuse (Maple, Short, Brown, Bryden, \& Salter, 2012). However, reports from these studies focused on findings and did not reflect on using online methods with victims. Moreover, gaps in research methodology could be identified in terms of the scarcity of qualitative methods' use. Although victims were facing overwhelming social and mental impact, qualitative research conducted to address how victims have coped with the situation in their own words was limited (Mishna, McLuckie, \& Saini, 2009). Sofronoff, Dark, and Stone (2011) focused on disabled people and included a qualitative element but that was through parents' perceptions on behalf of their children. This might not reflect the lived-experience because previous research showed differences in parents' knowledge on their children's online experiences (Sorbring \& Lundin, 2012). Due to the variations in definitions and figures discussed earlier, and the need to address the lived-experience using qualitative methods, mixed-method design provides a middle ground to scope cyber-victimisation experiences among people with disabilities, and subsequently identify victims to get input from them in their own words (Mayoh \& Onwuegbuzie, 2014).

Furthermore, there are gaps in studying the impact of cyber-victimisation and methods employed. Cybervictimisation was found to be comparable to offline victimisation in terms of causing fear, anxiety, depression, health complaints and self-harm (Dreßing et al., 2014; Yen et al., 2014). Additionally, social isolation and psychological consequences were more significant in cases of cyber-victimisation (Sheridan \& Grant, 2007; Short, Linford, Wheatcroft, \& Maple, 2014). Despite the documented evidence of its impact, there is limited literature focusing solely on cyber-victimisation effects on people with long term conditions and disabilities (Fridh et al., 2015). The documented consequences on people with disabilities included mental health complications such as depression, anxiety or suicide (Didden et al., 2009; Wells \& Mitchell, 2014) and somatic health complaints (Annerbäck et al., 2014; Fridh et al., 2015). However, these studies used a pre-determined set of questions in a cross-sectional design to report cyber-victimisation, indicating a gap in addressing the impact on specific conditions and in the flexibility of methods used.

In summary, the Internet has reshaped the documented victimisation against people with disabilities and this has a potential of imposing severe impact on victims. Research focusing on cyber-victimisation and its effects on people with disabilities is limited. This is paralleled by the use of online research methods in health and cyber abuse areas, but with limited qualitative element and reporting of online risks. In this paper we aim to examine methodological advantages and challenges encountered when employing online methods with people having chronic conditions and disabilities in a UK-based cyber-victimisation research.

\section{Methods}

\section{Using an Online Approach}

In this study, an internet-based approach was employed with the purpose of providing: a) a platform for a mixed-method online survey; b) a primary way to contact gatekeepers and provide relevant information on the research to generate interest; c) means to disseminate and publicize research links via social media, enewsletters and mailing lists; d) a method to allow volunteering by interested participants, via email, to arrange for in-depth interviewing; e) an alternative approach in interviewing by providing virtual interviewing (e.g Skype) as an option, if preferred by participants. The Internet was used to facilitate this research because online methods are recommended to increase response rates (Boynton \& Greenhalgh, 2004). Additionally, there were specific reasons to adopt online approaches with this particular target population because cyber victimisation victims suffer from social isolation and fear (Maple et al., 2011; Short et al., 2014) and people with disabilities might face physical difficulties in travelling (Quarmby, 2015; Sunderland, Chenoweth, Matthews, \& Ellem, 2014), which in both cases could limit reaching potential participants. However, reaching the participants was also influenced by the inclusion criteria and overall study design as discussed below.

\section{Study Design}

Sequential mixed-method design was adopted, it started with a quantitative phase followed by a qualitative phase. The quantitative element helped in scoping cyber-victimisation in the target population and the identification of "victims" as a sub-population to recruit for the second phase (De Korte-Verhoef et al., 2014; 
Krumholz, Curry, \& Bradley, 2011; Siddiqui \& Fitzgerald, 2014). Priority, which is the relative weight assigned to the quantitative or qualitative components of research (Kroll, Neri, \& Miller, 2005), was given to the qualitative element in this study. Qualitative methods are necessary to understand the lived-experience, especially for people with disabilities who need communicate what is important to them in their own words (Sunderland et al., 2014). Hence, this research is underpinned by a phenomenology as a philosophical stance (Husserl, 2012; Mayoh \& Onwuegbuzie, 2013). Victims of cyber abuse usually refer to the experience as a life changing traumatic event (Short et al., 2014). This description share similarities with the biographical disruption model (Bury, 1982), which describes developing a chronic disabling condition as a major disruptive life event that has long term consequences. Hence, we considered victims as experts in their own experiences, and in our interpretation we examined whether biographical disruption model was applicable to cyber-victimisation.

\section{Target Population}

This study included participants aged 18 years or older, residing in the UK, having a chronic condition and/or disability, and with mental capacity to consent according to the Mental Capacity Act 2005 (MCA, 2005). In the second stage, eligible participants who were victims of cyber abuse were invited to share their experiences in further detail. Participants from all genders, ethnic groups, religions, and occupations were included in accordance to the Equality Act 2010 (EA, 2010a) and to the Office for National Statistics' guidance (ONS, 2011, 2012). To ensure only eligible participants could fill the survey, a pre-screen showed at the beginning of the survey to confirm the eligibility criteria. Any missing criterion was designed to lead to a "thank you" note and the end of survey.

\section{Ethical Considerations and Risk Assessment}

Formal ethical permission was granted by the ethics committee at the University of Bedfordshire. Due to the vulnerability of participants, the National Health Service (NHS) Research Ethics Committee (REC) and Disclosure and Barring Service (DBS) were contacted in the UK to confirm that no further approvals were needed. A full risk assessment was made to ensure causing no harm to participants, protecting them, promoting good and respecting participants' autonomy (BPS, 2010; DH, 2005; Wiles, 2012). The survey starts with a briefing consent, while written and verbal consents were taken before interviews. Anonymity, confidentiality and the right to skip questions or withdraw at any time without giving a reason were explained to the participants before commencing the survey or the interview. Participants were debriefed, and contact details were provided for further information or to complain. Upon participation, further support was available to participants in terms of practical advice, reading materials and contact details of a number of helpful organisations.

\section{Survey and Interview Structure}

The first phase started with a survey that was made available online for 18 months, starting from September 2015. The survey was developed following literature review and input from experts in the fields of health and cyber abuse. It was further piloted with patients and professionals in the field, and minor changes were made to ensure the clarity of language and survey functionality. The first two sections of the survey were designed to capture demographic data and information on the health condition such as duration, coping and management plan. When multiple conditions were reported, participants were provided with a space to write the condition that affected them most from their own perception.

The third section focused on cyber-victimisation experiences. For participants to be able to answer questions in this section they were either self-identified victims by responding "yes" to the question: "Do you consider yourself to be a victim of online harassment/cyberstalking?", or responding "yes" to the question "Have you ever experienced that someone unwantedly contacted you repeatedly (more than once) via the Internet such as email, chartroom, online forum, social network, mobile phone message, or other electronic means and used it to harass, insult, embarrass, or spread lies about you?". Options provided were "yes", "no" and "not sure". An explanatory page was designed to inform participants that they were eligible to fill the next set of questions assuming that it was a cyber-victimisation experience. The section consists of both closed-ended and openended questions about cyber-victimisation experience, such as duration, frequency, means used, impact on them and support sought. Boxes to write free text were available throughout this section. Participants were also 
provided with a number of themes/statements documented in previous research and were asked to endorse the statements that represent their situation. This was on a 5-point likert scale ranging from "never" to "always". A validated self-management assessment tool, Stanford self-efficacy scale (Lorig et al., 2001; Lorig, Sobel, Ritter, Laurent, \& Hobbs, 2000; Ramey, Raynauld, \& Fries, 1992; Stanford, 2015) was incorporated to look at the perceived impact on self-management of the heath conditions. Upon completing the survey, participants were given the option to volunteer for the second phase by ticking a box in the questionnaire and providing their email addresses to arrange for in-depth interviews.

\section{Engagement with Gatekeepers}

Online recruitment was through victim-support groups, patient-support groups, and social media. Search engines were used to identify victim and health support groups as sources for recruitment, keywords used included: patient, support, chronic, health forum, disability, hate crime, online-support, and specific health conditions' names. The search results were short-listed, we identified "gatekeepers" based on the criteria of being: a) established patient and victim support groups/organisations; b) based in the UK or with significant audience from the UK; $c$ ) having terms and policies in their websites aligning with ethics to protect participants (BPS, 2010); d) having direct contact with patients/victims; e) provided contact details. Further snowballing was followed to reach relevant organisations/charities or journalists, academics and activists in the field. The primary researcher contacted "gatekeepers" via email, when no response was received within 1-2 weeks an email reminder was sent. In cases where a telephone number was provided, further contact via phone was made. Gatekeepers were provided with information related to the rationale of the study, expected benefits to participants in short and long term, inclusion criteria, the survey link, study poster and contact details. To generate interest, in each time a gatekeeper was contacted the request letter was tailored specifically to the audience in that group.

\section{Results}

A total of 80 gatekeepers were approached to help in recruiting participants for this research, 63 (78.8\%) responded to the request, and 51(63.8\%) accepted to help as summarised in table (1). Acceptance implied actively publicizing the link to the survey via social media, newsletters, webpages or mailing lists. It is estimated that each gatekeeper generated interest from 0-3 participants.

Table 1. Categories of Gatekeepers Approached for Recruitment and their Responses in $n(\%)$.

\begin{tabular}{lllll}
\hline $\begin{array}{l}\text { Gatekeeper } \\
\text { Category }\end{array}$ & Accepted & Declined & Pending & Total \\
\hline $\begin{array}{l}\text { Patient support } \\
\text { groups/organisations }\end{array}$ & 20 & 11 & 13 & 44 \\
$\begin{array}{l}\text { Victim support } \\
\text { groups/organisations }\end{array}$ & 20 & 0 & 1 & 21 \\
$\begin{array}{l}\text { Other groups } \\
\text { Total }\end{array}$ & 11 & 1 & 3 & 15 \\
\hline
\end{tabular}

To reflect on the recruitment process, we examined the responses from gatekeepers and subsequent interactions by the respondents. The sources of data included in this paper are :1) responses from gatekeepers received via email, phone calls or social media interactions, 2) responses from participants which were in the form of written or verbal feedback before or during interviews, 3) researcher's notes and observations following each wave of recruitment by individual gatekeepers. As the aim of this paper is to reflect on methodological challenges and guide future research, we grouped all these responses and looked for patterns to identify challenges or facilitators of using online research methods with people with disabilities who were victimised. The responses were read and re-read, and further categorised in an approach sympathetic to thematic analysis (Braun \& Clarke, 2006). We found that recruitment and data collection were challenged by four overarching themes: social identity in online support groups, the role of online gatekeepers, the contradictory role of social media, and promoting inclusivity. 


\section{Social Identity in Online Support Groups}

Social identity was identified as a factor influencing reactions in virtual communities. Viewing self as a disabled person, victim, or having an invisible disability or a mental health condition revealed higher motivation to participate. Participants who identified themselves as "disabled" were more responsive to communication especially when they were enrolled in groups working against disability hate crime. Having an "invisible disability" also seemed to be influencing participants' attitudes towards sharing their experiences. This was seen particularly in online patient support groups; people with invisible disabilities were cooperative to make their voices heard. They seemed to be struggling to legitimise their conditions and challenge the prejudice and hostility against them. One of the participants with Myalgic Encephalomyelitis (ME) shared:

The online ME community are marvellous. We support each other. The ME community is almost unique in that, by the nature of the condition, we are almost entirely online, so are very protective of each other, and very quick to dismiss and discredit the numerous snake oil salesmen and false friends. Another unusual aspect of ME is that we are fighting a battle against the psychosocial model that has been foisted on us. Although ME is classified by World Health Organisation as a neurological condition, in UK it is treated as psychological, so we are always fighting the misinformation, medical mistreatment and belittling of our condition. Many of us have become this ill because we pushed ourselves too hard when we first became ill (...) We fight well, despite being so ill. (Participant B4)

Participants who identified themselves as "victims" were also keen to participate, this was specific to cyberharassment victims who just wanted to be heard. They shared their experiences in a detailed manner and explained how negative internet interactions had real impact on their lives. People recruited from mental health support groups shared the same appreciation towards being heard. However, other online groups' members were cautious in dealing with "outsiders", being academics or healthcare professionals. This was revealed during recruitment arrangements when a participant - who was also a gatekeeper- explained how the word "spoonie" reflects their experiences more than medical terms. Spoonie is a term adopted by people living with chronic illnesses and disabilities. The name came from "The Spoon Theory" which was first described by a blogger living with lupus, she used spoons to illustrate to her friend the limited choices people with chronic conditions face in their daily life. The term spoonie was then derived and largely adopted by people with chronic illnesses and disabilities in online communities.

\section{The Role of Online Gatekeepers}

Online-gatekeepers had a challenging role in reaching participants with disabilities. This was based on the size of the organisation/group, fees and funding issues, type of audience, and the role of volunteers. Most wellestablished organisations with thousands of members in their online communities had a pre-determined policy in responding to research requests, for example, having an online form to ask for help in recruitment. Response from such organisations was taking time but guaranteed the reach to high numbers of eligible participants, however this did not necessarily result in actual participation. Another challenge linked to gatekeepers of large online communities was issues related to fees and funding, which was mostly faced with patient-support groups. Some organisations declined the help request because their social media accounts support only research funded by their establishment, while other organisations requested fees to publicise research with them.

The type of audience associated with gatekeepers has also influenced the decision to support recruitment. Some patient-support groups were protective of their members, this was seen in some groups for chronic illness and physical disabilities who declined due to data protection issues. While one gatekeeper supporting people with mental health conditions and intellectual disabilities was protective of members due to uncertainty about the capacity to consent. However, gatekeepers from victim support groups and charities were very responsive and prioritised sharing the research with their members as a means of support to them.

In cases where gatekeepers were volunteers in charities who were themselves coping with disabling conditions the response was influenced by gatekeepers' health condition and previous victimisation experiences. The responses ranged from showing interest but apologising due to health and human resources issue, to acceptance and dissemination of research links especially in the case of invisible disabilities. 


\section{The Contradictory Role of Social Media}

Using social media accounts to promote the link to the survey depended on the "right" pages to share or tweet the call for participants. Facebook and twitter accounts were used, but twitter was generally more effective in reaching the target population. When gatekeepers' accounts tweeted the link to the survey the response from online followers was immediate. However, immediate response means two or three people interacting with the research link out of thousands of followers per each tweet. The effect of the tweet was also short term; it did not exceed few hours after which no more interactions, i.e retweets, were observed.

Social media accounts of activists trusted by people with disabilities such as disability-support groups, disabled bloggers, or active journalists against disability hate crimes resulted in snowballing of the link. These were as effective as larger established support groups' accounts. Tweets by popular academics in health or cyber abuse areas resulted in further interactions by academic and professionals but did not necessarily reach eligible participants. Hence, the use of any hashtag related to \#spoonie reached targeted population more than scientific words.

\section{Promoting Inclusivity}

Inclusivity appeared to be a potential advantage of using online-recruitment and interviews. Online dissemination of the survey link helped to reach diverse participants and remote geographical areas, which could reflect diverse victim experiences. When in-depth interviews were conducted, inclusivity was promoted by providing virtual interviewing via Skype as an option. This alternative was preferred by most of the participants. People with disabilities implied that online interviewing accommodated their needs in terms of physical mobility, time constraints, or to avoid exhaustive travelling. Furthermore, inclusivity was addressed in cyberharassment cases by overcoming victims' social isolation. This was through giving them the chance to participate despite their fears of safety and/or social anxieties following this traumatic experience. Some victims explicitly shared their fears while planning for the interview and others created new Skype accounts to ensure helping others by informing this research. Despite these observed benefits, inclusivity was also a challenge due to the heterogeneity of conditions categorised as disabilities, which required researchers' sensitivity to individual needs. For example, one participant with disability preferred online interviewing due to physical disability, but also could not cope with real-life online interaction and preferred to type the answers due to co-morbidities affecting dialogue.

\section{Discussion}

Using online-based approaches in recruiting participants from 80 patient and victim support groups has revealed a number of challenges and advantages of using these methods with people having long term conditions and disabilities in cyber-victimisation research. These were related to the target population, gatekeepers and the use of social media.

One of the main challenges identified was the existing online identity of participants. Presenting self with a status of being a victim, disabled, or having an invisible illness has increased the motivation to participate in research. Disability identity is a known area of research, it could be defined as the positive sense of self and feelings, it helps to cope, and find solidarity with the disabled community (Dunn \& Burcaw, 2013). In this study, participation could be influenced by representing the identity of disabled and/or victimised groups, to express the group's opinion or help in improving support to them by sharing own victimisation experiences. Some of the key aspects of disability identity described in previous studies were finding a personal meaning, attachments in disability group membership, and being a target of discrimination (Dunn \& Burcaw, 2013). Discrimination as part of the disability identity is consistent with our findings, however, the role of online communities could have influenced the representation of this part of self-identification. For example, a previous review of challenges in using online methods with students having disabilities identified a possible bias in representing self because disabled students tended to provide a positive self-image (De Cesarei \& Baldaro, 2015). In this paper this was not the case, the mixture of disability and victim status resulted into representing self differently, by affirming disability status and using the illness experience for self-expression. It is also possible that online communities 
have empowered disabled and/or victimised populations to acknowledge the victim status and stand against discrimination.

The presence of identity across identified challenges could be explained by the Social Identity Theory, in which the personal image is enhanced through group membership, resulting into an "in-group" and an "out-group" categorisation with tendency of bias towards the in-group (Tajfel, 2010; Turner, Brown, \& Tajfel, 1979). Based on this explanation, illustrated in figure (1), people with disabilities go through the process of developing a personal identity followed by social categorisation. In this process the in-group is the disabled community. When being part of this community the outcome of inter-group comparison process results in empowerment and encourages participation in research. Alternatively, not identifying self as part of the disabled in-group could result in perceived discrimination and further isolation from the community or other activities such as research.

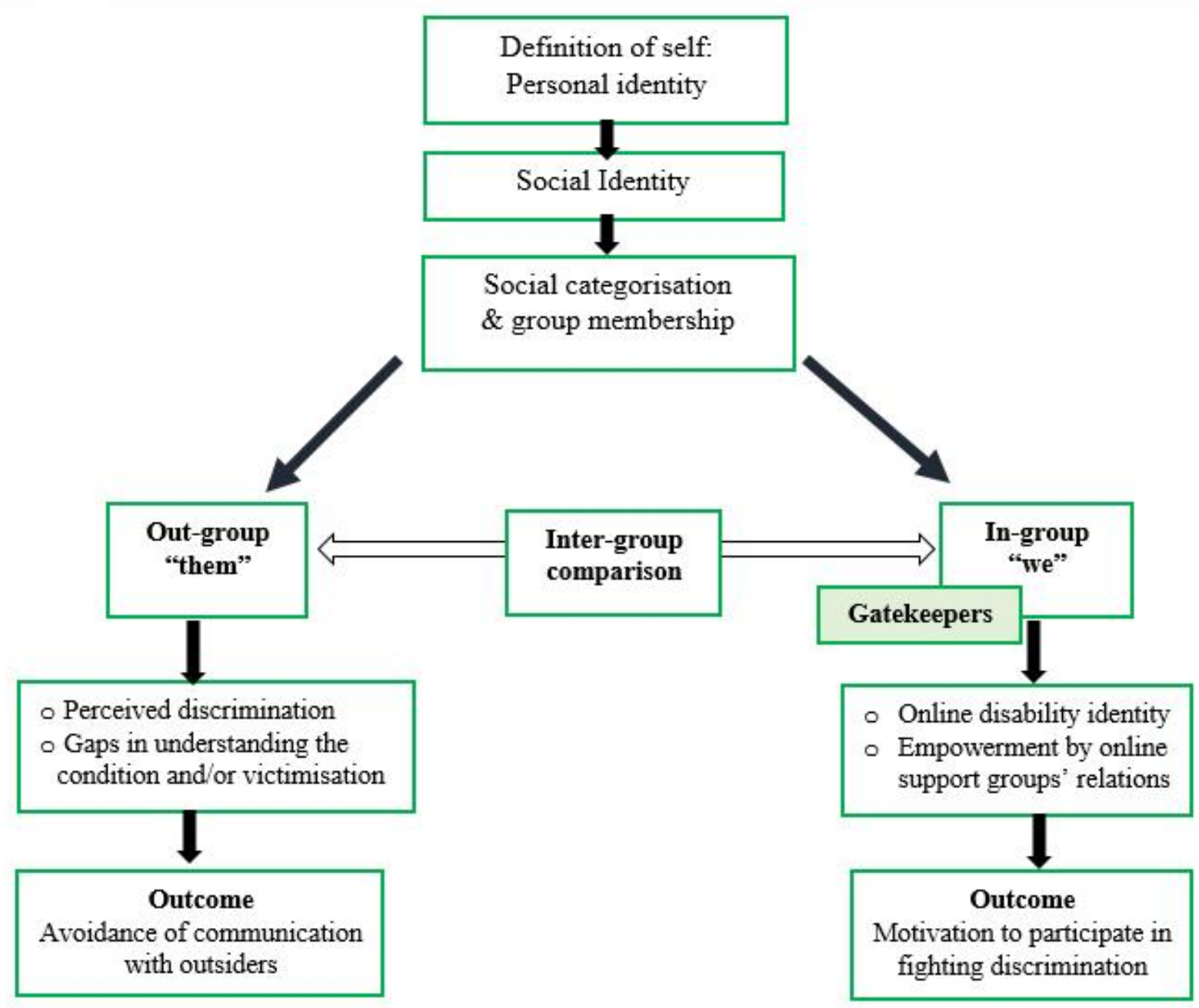

Figure 1. Social Identity Theory and cyber victimisation of people with chronic conditions and disabilities, adopted from (Turner et al., 1979).

The identification of specific aspects of online self-representation of disabled people was recommended in previous research (Molin, Sorbring, \& Löfgren-Mårtenson, 2015), and if accompanied by highlighting positive aspect of online identity (Dunn \& Burcaw, 2013) improvements in research methods could be seen. Hence, in this study we observed how having an existing online identity related to victim status or certain disabilities maximised the potential of involving vulnerable groups to enhance their voices in research.

The online identity of people with disabilities can also be a barrier to participation; differences between the target population and the researchers/academics were recognised. These differences were mainly seen in 
interactions with social media accounts and in terminology used. Participants reacted to the requests publicised by people fighting for their cases such as activists against disability hate crime. Hence, pre-established relations and trust could have influenced the decision to participate. This highlights the need for mutual-trust for a productive recruitment process (Cohn, 2015). While considering the terminology used, adjusting hashtags to adopt terms common among disabled people such as \#spoonie, resulted in higher engagement by participants, but the use of this term was very limited in academic literature. Upon further search on the use of the word spoonie -and its derivatives- in social media, it appeared to be used widely by users to refer to disability and chronic illness (Miserandino, 2003). While upon searching in research databases very few results hardly mention The Spoon Theory, such using it as an example of internet activism (Dingwall-Jones, 2014) or to discuss the need to understand the illness experience (Biro, 2012; Jackson, 2013). In a published dissertation, disabled participants brought The Spoon Theory in their narratives to communicate and express themselves (Miller, 2015), which was encountered during this study too. Hence, understanding how people with disabilities represent themselves and trust-building in research are necessary in online recruitment and in designing future research.

The finding of this paper addresses those methodological concerns regarding the role of gatekeepers. It is documented that gatekeepers could assists in reaching disabled participants, however gatekeepers' role in literature was considered challenging because of delaying research, or denying the opportunity to participate due to over-protection (Goldsmith \& Skirton, 2015). In this study, the over-protection was anticipated from victim support groups due to the sensitivity of the topic, and from groups for people with mental health illness and intellectual disabilities due to mental capacity issues. However, upon contacting the gatekeepers protection came from support groups for chronic illnesses and one group for people with intellectual disabilities. While groups supporting victims of cyber abuse who suffer from PTSD and other mental health consequences were more motivated. This could be explained by these groups' sympathetic aims to support participants, or could be linked to the social identities too. This is because groups using medical conditions to represent themselves are already legitimised to the public compared to groups of people having invisible illnesses or victims of online abuse. Further, cyber-victimisation is only recently recognised, its impact on disabled people is under research, and there are assumptions by informal and formal support channels underestimating the impact of what happens on the internet (al-Khateeb, Epiphaniou, Alhaboby, Barnes, \& Short, 2016). These assumption undermines social support, which is necessary for victimised disabled people (Fridh et al., 2015). Hence, these factors could have encouraged victim support groups to publicize this research to improve services available.

Further to trust and status legitimisation in relation to gatekeepers, another documented challenge is perceived power imbalance and priorities between gatekeepers and potential participants (Carlson, 2013; Goldsmith \& Skirton, 2015). It is possible that online recruitment minimised this imbalance because in our study participants who saw their gatekeepers promoting the study on social media did not necessarily interact with the link. Gatekeepers' role was also limited by funding issues, which is a documented concern in previous research when the gatekeepers had different agenda from researchers (Wiles, Crow, Charles, \& Heath, 2007). This was further complicated in in some cases where the online identity and gatekeepers' agenda aligned, but capacity and resources available were scarce. This issue is also consistent with previous work showing how gatekeepers might limit access to participants when their resources are limited (Nind, 2009).

The potential of using online research methods was promising in terms of addressing inclusivity and diversity people with disabilities and victims. This research confirmed previous work suggesting the role of online methods to reach people with disabilities with less cost and encourage disabled people to talk openly more than face to face (Morris, 2013; Sunderland et al., 2014). Such approach helped in addressing diversity but did not guarantee high numbers of participants probably due to the sensitivity of the topic in this study. However, online methods responded to the vulnerabilities accompanying being a disabled person and a victim of cyber abuse by overcoming fears and physical, social, or emotional barriers.

It is to be acknowledged that one of the main research approaches to tackle oppression and improve inclusivity is community based-participatory research. It could be considered as a partnership between the researcher and the researched in which the knowledge results from peoples' participation in defining issues of concern to them and solving them (Bate, 2000). Participatory action research makes no definite discrimination between the researchers and researched (Meyer, 2000). It was adopted with people having disabilities due to its values of 
empowerment and contribution to social change (Nind \& Vinha, 2014). It challenges exclusion in the research process by involving people with disabilities to develop the research project, conduct and analyse data in a continuous cycle of learning (Buettgen et al., 2012). Participatory research was also used to create accessible instruments for individuals with developmental disabilities (Nicolaidis et al., 2015). Because this project is one of the earliest studies to examine cyber-victimisation of people with different types of disabilities, and due to the sensitivity of the issue, a preliminary scoping of the phenomenon and sensitive approach to victims were needed, hence a participatory action research could not be fully adopted. However, our findings will help in designing further research with participatory nature and higher chances of engaging participants at all stages of the research process.

The discussed challenges and advantages in this article are limited by a number of factors. Similar to other research (Carlson, 2013; Morris, 2013), one limitation is the inadequate opportunity given to participants with intellectual disabilities due to their gatekeepers' responses or their capacity to consent. This could be overcome by tailoring consent and content to their needs and offering sufficient support, which could be challenging (Goldsmith \& Skirton, 2015). Another limitation is access by people with limiting disabilities, such as visual and motor impairments, hence the format or length of questions could be tiring or requiring further adjustments (De Cesarei \& Baldaro, 2015). Lack of access and socioeconomic status are also key limitations to online research methods (Sunderland et al., 2014). Despite these limitations, the findings in this paper could provide an insight of the potential of using online research methods with vulnerable groups, and will guide future research to do further modifications to ensure overcoming the identified challenges.

In conclusion, the Internet has aggravated the vulnerability of people with disabilities, but it also has a huge potential in researching sensitive topics with this group. Challenges identified were related to online identity, gate keepers' responses, social media use and addressing diversity through promoting inclusivity. The developed online identity was a common factor contributing to all described themes, which could be considered as a challenge, but also a potential facilitator in research if it is acknowledged by researchers. This could be achieved by considering the characteristics of online self-representation of people with disabilities more specifically, accompanied by highlighting positive aspect of online identity to provide tailored research methods or interventions. For instance, positive aspects identified included viewing self with the status of being a disabled, victim, or having invisible illnesses in internet communities, and online inclusivity. These could be potential points to consider during early stages in future research with disabled victimised people.

\section{Acknowledgments}

We would like to thank all people and groups who supported this research.

\section{References}

al-Khateeb, H. M., Epiphaniou, G., Alhaboby, Z. A., Barnes, J., \& Short, E. (2016). Cyberstalking: Investigating Formal Intervention and the Role of Corporate Social Responsibility. Telematics and Informatics. Advanced online publication. http://dx.doi.org/10.1016/j.tele.2016.08.016

Alhaboby, Z. A., al-Khateeb, H. M., Barnes, J., \& Short, E. (2016). The language is disgusting and they refer to my disability: The cyberharassment of disabled people. Disability \& Society, 31, 1138-1143.

http://dx.doi.org/10.1080/09687599.2016.1235313

Anastasiou, D., \& Kauffman, J. M. (2013). The social model of disability: Dichotomy between impairment and disability. Journal of Medicine and Philosophy, 38, 441-459. http://dx.doi.org/10.1093/jmp/jht026

Annerbäck, E.-M., Sahlqvist, L., \& Wingren, G. (2014). A cross-sectional study of victimisation of bullying among schoolchildren in Sweden: Background factors and self-reported health complaints. Scandinavian Journal of Public Health, 42, 270-277. http://dx.doi.org/10.1177/1403494813514142

Anastasiou, D., \& Kauffman, J. M. (2013). The social model of disability: Dichotomy between impairment and disability. Journal of Medicine and Philosophy, 38, 441-459. http://dx.doi.org/10.1093/jmp/jht026 
Annerbäck, E.-M., Sahlqvist, L., \& Wingren, G. (2014). A cross-sectional study of victimisation of bullying among schoolchildren in Sweden: Background factors and self-reported health complaints. Scandinavian Journal of Public Health, 42, 270-277. http://dx.doi.org/10.1177/1403494813514142

Bate, P. (2000). Synthesizing research and practice: Using the action research approach in health care settings. Social Policy \& Administration, 34, 478-493. http://dx.doi.org/10.1111/1467-9515.00205

Biro, D. (2012). An anatomy of illness. Journal of Medical Humanities, 33, 41-54. http://dx.doi.org/10.1007/s10912011-9161-5

Boynton, P. M., \& Greenhalgh, T. (2004). Selecting, designing, and developing your questionnaire. BMJ, 328, 1312 1315. http://dx.doi.org/10.1136/bmj.328.7451.1312

BPS. (2010). Code of Human Research Ethics. Leicester : British Psychological Society.

Braun, V., \& Clarke, V. (2006). Using thematic analysis in psychology. Qualitative Research in Psychology, 3, 77-101. http://dx.doi.org/10.1191/1478088706qp063oa

Buettgen, A., Richardson, J., Beckham, K., Richardson, K., Ward, M., \& Riemer, M. (2012). We did it together: A participatory action research study on poverty and disability. Disability \& Society, 27, 603-616.

http://dx.doi.org/10.1080/09687599.2012.669106

Buijs, P., Boot, E., Shugar, A., Fung, W. L. A., \& Bassett, A. S. (2016). Internet safety issues for adolescents and adults with intellectual disabilities. Journal of Applied Research in Intellectual Disabilities, 30, 416-418.

http://dx.doi.org/10.1111/jar.12250

Bury, M. (1982). Chronic illness as biographical disruption. Sociology of Health \& Illness, 4, 167-182.

http://dx.doi.org/10.1111/1467-9566.ep11339939

Carlson, L. (2013). Research ethics and intellectual disability: Broadening the debates. The Yale journal of biology and medicine, 86, 303-314.

Cohn, S. (2015). 'Trust my doctor, trust my pancreas': Trust as an emergent quality of social practice. Philosophy, Ethics, and Humanities in Medicine, 10, 9. http://dx.doi.org/10.1186/s13010-015-0029-6

Coulson, N. S. (2015). Exploring patients' engagement with web-based peer support for Inflammatory Bowel Disease: Forums or Facebook? Health Psychology Update, 24(2), 3-8.

De Cesarei, A., \& Baldaro, B. (2015). Doing online research involving university students with disabilities: Methodological issues. Computers in Human Behavior, 53, 374-380. http://dx.doi.org/10.1016/j.chb.2015.07.028

De Korte-Verhoef, M. C., Pasman, H. R. W., Schweitzer, B. P., Francke, A. L., Onwuteaka-Philipsen, B. D., \& Deliens, L. (2014). General practitioners' perspectives on the avoidability of hospitalizations at the end of life: A mixedmethod study. Palliative medicine, 28, 949-958. http://dx.doi.org/10.1177/0269216314528742

DH. (2005). Research Governance Framework for Health and Social Care. Department of Health.

Didden, R., Scholte, R. H. J., Korzilius, H., de Moor, J. M., Vermeulen, A., O'Reilly, M., . . Lancioni, G. E. (2009). Cyberbullying among students with intellectual and developmental disability in special education settings. Developmental Neurorehabilitation, 12, 146-151 146p. http://dx.doi.org/10.1080/17518420902971356

Dingwall-Jones, C. (2014). "Antic dispositions?" The representation of madness in modern British theatre. University of Kent.

Dreßing, H., Bailer, J., Anders, A., Wagner, H., \& Gallas, C. (2014). Cyberstalking in a large sample of social network users: Prevalence, characteristics, and impact upon victims. Cyberpsychology, Behavior, and Social Networking, 17, 61-67. http://dx.doi.org/10.1089/cyber.2012.0231

Dunn, D. S., \& Burcaw, S. (2013). Disability identity: Exploring narrative accounts of disability. Rehabilitation Psychology, 58, 148-157. http://dx.doi.org/10.1037/a0031691

EA. (2010a). Equality Act 2010: Chapter 15. 
EA. (2010b). Guidance on matters to be taken into account in determining questions relating to the definition of disability Equality Act 2010.

Emerson, E., \& Roulstone, A. (2014). Developing an evidence base for violent and disablist hate crime in Britain: Findings From the Life Opportunities Survey. Journal of Interpersonal Violence, 29, 3086-3104. http://dx.doi.org/10.1177/0886260514534524

Forhan, M. (2009). An analysis of disability models and the application of the ICF to obesity. Disability and rehabilitation, 31, 1382-1388. http://dx.doi.org/10.1080/09638280802572981

Fox, S., \& Purcell, K. (2010). Chronic disease and the internet. Pew Internet \& American Life Project.

Fridh, M., Lindström, M., \& Rosvall, M. (2015). Subjective health complaints in adolescent victims of cyber harassment: Moderation through support from parents/friends - a Swedish population-based study. BMC Public Health, 15, 949-949. http://dx.doi.org/10.1186/s12889-015-2239-7

Goldsmith, L., \& Skirton, H. (2015). Research involving people with a learning disability-methodological challenges and ethical considerations. Journal of Research in Nursing, 20, 435-446.

http://dx.doi.org/10.1177/1744987115591867

Gustafson, D. L., \& Brunger, F. (2014). Ethics,"vulnerability," and feminist participatory action research with a disability community. Qualitative Health Research, 24, 997-1005. http://dx.doi.org/10.1177/1049732314538122

Hinder, S., \& Greenhalgh, T. (2012). This does my head in Ethnographic study of self-management by people with diabetes. BMC Health Serv Res, 12(1), 83. http://dx.doi.org/10.1186/1472-6963-12-83

Horowitz, J. A., Vessey, J. A., Carlson, K. L., Bradley, J. F., Montoya, C., McCullough, B., \& David, J. (2004). Teasing and bullying experiences of middle school students. Journal of the American Psychiatric Nurses Association, 10, 165172. http://dx.doi.org/10.1177/1078390304267862

Hugh-Jones, S., \& Smith, P. K. (1999). Self-reports of short- and long-term effects of bullying on children who stammer. British Journal of Educational Psychology, 69, 141-158. http://dx.doi.org/10.1348/000709999157626

Humpage, L. (2007). Models of disability, work and welfare in Australia. Social Policy \& Administration, 41, 215-231. http://dx.doi.org/10.1111/j.1467-9515.2007.00549.x

Husserl, E. (2012). Logical investigations (Vol. 1): Routledge.

Jackson, M. (2013). The special educational needs of adolescents living with chronic illness: A literature review. International Journal of Inclusive Education, 17, 543-554. http://dx.doi.org/10.1080/13603116.2012.676085

Kipnis, K. (2001). Vulnerability in research subjects: A bioethical taxonomy. Ethical and policy issues in research involving human participants, 2.

Kouwenberg, M., Rieffe, C., Theunissen, S. C. P. M., \& de Rooij, M. (2012). Peer victimization experienced by children and adolescents who are deaf or hard of hearing. PLOS ONE, 7(12), e52174-e52174.

http://dx.doi.org/10.1371/journal.pone.0052174

Kowalski, R. M., \& Fedina, C. (2011). Cyber bullying in ADHD and Asperger Syndrome populations. Research in Autism Spectrum Disorders, 5, 1201-1208. http://dx.doi.org/10.1016/j.rasd.2011.01.007

Kroll, T., Neri, M. T., \& Miller, K. (2005). Using mixed methods in disability and rehabilitation research. Rehabilitation Nursing, 30, 106-113. http://dx.doi.org/10.1002/j.2048-7940.2005.tb00372.x

Krumholz, H. M., Curry, L. A., \& Bradley, E. H. (2011). Survival after acute myocardial infarction (SAMI) study: the design and implementation of a positive deviance study. American Heart Journal, 162, 981-987.

http://dx.doi.org/10.1016/j.ahj.2011.09.004

Levine, C., Faden, R., Grady, C., Hammerschmidt, D., Eckenwiler, L., \& Sugarman, J. (2004). The limitations of "vulnerability" as a protection for human research participants. The American Journal of Bioethics, 4, 44-49.

http://dx.doi.org/10.1080/15265160490497083 
Lorig, K. R., Ritter, P., Stewart, A. L., Sobel, D. S., Brown Jr, B. W., Bandura, A., .. Holman, H. R. (2001). Chronic disease self-management program: 2-year health status and health care utilization outcomes. Medical care, 39, 1217-1223. http://dx.doi.org/10.1097/00005650-200111000-00008

Lorig, K. R., Ritter, P. L., Laurent, D. D., \& Plant, K. (2006). Internet-based chronic disease self-management: A randomized trial. Medical care, 44, 964-971. http://dx.doi.org/10.1097/01.mlr.0000233678.80203.c1

Lorig, K. R., Sobel, D. S., Ritter, P. L., Laurent, D., \& Hobbs, M. (2000). Effect of a self-management program on patients with chronic disease. Effective Clinical Practice: ECP, 4, 256-262.

Maple, C., Short, E., \& Brown, A. (2011). Cyberstalking in the United Kingdom: An analysis of the ECHO pilot survey. National Centre for Cyberstalking Research: University of Bedfordshire.

Maple, C., Short, E., Brown, A., Bryden, C., \& Salter, M. (2012). Cyberstalking in the UK: Analysis and Recommendations. International Journal of Distributed Systems and Technologies (IJDST), 3(4), 34-51.

Mayoh, J., \& Onwuegbuzie, A. J. (2013). Toward a conceptualization of mixed methods phenomenological research. Journal of Mixed Methods Research, 9, 91-107. http://dx.doi.org/10.1177/1558689813505358

Mayoh, J., \& Onwuegbuzie, A. J. (2014). Surveying the landscape of mixed methods phenomenological research. International Journal of Multiple Research Approaches, 8(1), 2-14. http://dx.doi.org/10.5172/mra.2014.8.1.2

MCA. (2005). Mental Capacity Act: Code of Practice. Department for Constitutional Affairs. London: TSO.

McDermott, M. S., \& While, A. E. (2013). Maximizing the healthcare environment: A systematic review exploring the potential of computer technology to promote self-management of chronic illness in healthcare settings. Patient Education and Counseling, 92, 13-22. http://dx.doi.org/10.1016/j.pec.2013.02.014

Merolli, M., Gray, K., \& Martin-Sanchez, F. (2013). Health outcomes and related effects of using social media in chronic disease management: A literature review and analysis of affordances. Journal of Biomedical Informatics, 46, 957-969. http://dx.doi.org/10.1016/j.jbi.2013.04.010

Meyer, J. (2000). Using qualitative methods in health related action research. BMJ, 320(7228), 178-181. http://dx.doi.org/10.1136/bmj.320.7228.178

Miller, R. A. (2015). Intersections of disability, gender, and sexuality in higher education: exploring students' social identities and campus experiences [dissertation]. Austin: The University of Texas at Austin.

Miserandino, C. (2003). The Spoon Theory. Retrieved from http://www.butyoudontlooksick.com/articles/writtenby-christine/the-spoon-theory/

Mishna, F., McLuckie, A., \& Saini, M. (2009). Real-world dangers in an online reality: A qualitative study examining online relationships and cyber abuse. Social Work Research, 33, 107-118. http://dx.doi.org/10.1093/swr/33.2.107

Molin, M., Sorbring, E., \& Löfgren-Mårtenson, L. (2015). Teachers' and parents' views on the Internet and social media usage by pupils with intellectual disabilities. Journal of Intellectual Disabilities, 19, 22-33.

http://dx.doi.org/10.1177/1744629514563558

Morris, R. (2013). 'Unjust, inhumane and highly inaccurate': the impact of changes to disability benefits and services-social media as a tool in research and activism. Disability \& Society, 28, 724-728.

http://dx.doi.org/10.1080/09687599.2013.808093

Nicolaidis, C., Raymaker, D., Katz, M., Oschwald, M., Goe, R., Leotti, S., . . Hughes, R. B. (2015). Community-based participatory research to adapt health measures for use by people with developmental disabilities. Progress in Community Health Partnerships: Research, Education, And Action, 9, 157-170.

http://dx.doi.org/10.1353/cpr.2015.0037

Nind, M. (2009). Conducting qualitative research with people with learning, communication and other disabilities: Methodological challenges. ESRC National Centre for Research Methods Review Paper. National Centre for Research Methods. Retrieved from https://eprints.soton.ac.uk/65065/1/MethodsReviewPaperNCRM-012.pdf

Nind, M., \& Vinha, H. (2014). Doing research inclusively: Bridges to multiple possibilities in inclusive research.

British Journal of Learning Disabilities, 42, 102-109. http://dx.doi.org/10.1111/bld.12013 
Normand, C. L., \& Sallafranque-St-Louis, F. (2016). Cybervictimization of young people with an intellectual or developmental disability: Risks specific to sexual solicitation. Journal of Applied Research in Intellectual Disabilities, 29, 99-110. http://dx.doi.org/10.1111/jar.12163

O'connor, A., Jackson, L., Goldsmith, L., \& Skirton, H. (2014). Can I get a retweet please? Health research recruitment and the Twittersphere. Journal of Advanced Nursing, 70, 599-609. http://dx.doi.org/10.1111/jan.12222

ODI. (2014). Disability prevalence estimates Office for Disability Issues.

ONS. (2011). Population Estimates by Ethnic Group: Methodology Paper. Office for National Statistics

ONS. (2012). Office for National Statistics: Ethnicity and National Identity in England and Wales 2011.

ONS. (2014). Internet Access - Households and Individuals 2014. Retrieved from

http://www.ons.gov.uk/peoplepopulationandcommunity/householdcharacteristics/homeinternetandsocialmedia usage/bulletins/internetaccesshouseholdsandindividuals/2014-08-07

Quarmby, K. (2011). Scapegoat: How we are failing disabled people: London: Portobello Books.

Quarmby, K. (2015). Disability hate crime motivation survey - results. Retrieved from

https://katharinequarmby.wordpress.com

Ramey, D. R., Raynauld, J. P., \& Fries, J. F. (1992). The health assessment questionnaire 1992: Status and review. Arthritis Care \& Research, 5, 119-129. http://dx.doi.org/10.1002/art.1790050303

Richardson, L., Beadle-Brown, J., Bradshaw, J., Guest, C., Malovic, A., Himmerich, J., . . McGill, P. (2016). 'I felt that I deserved it'-experiences and implications of disability hate crime. Tizard Learning Disability Review, 21, 80-88. http://dx.doi.org/10.1108/tldr-03-2015-0010

Sentenac, M., Arnaud, C., Gavin, A., Molcho, M., Gabhainn, S. N., \& Godeau, E. (2011). Peer victimization among school-aged children with chronic conditions. Epidemiologic Reviews, 34, 120-128.

http://dx.doi.org/10.1093/epirev/mxr024

Sentenac, M., Gavin, A., Gabhainn, S. N., Molcho, M., Due, P., Ravens-Sieberer, U., . . Godeau, E. (2013). Peer victimization and subjective health among students reporting disability or chronic illness in 11 Western countries. European Journal of Public Health, 23, 421-426. http://dx.doi.org/10.1093/eurpub/cks073

Sheridan, L. P., \& Grant, T. (2007). Is cyberstalking different? Psychology, Crime \& Law, 13, 627-640.

Short, E., Linford, S., Wheatcroft, J. M., \& Maple, C. (2014). The impact of cyberstalking: The lived experience - a thematic analysis. Stud Health Technol Inform, 199, 133-137.

Siddiqui, N., \& Fitzgerald, A. (2014). Elaborated integration of qualitative and quantitative perspectives in mixed methods research: A profound enquiry into the nursing practice environment. Journal of Multiple Research Approaches, 8, 137-147. http://dx.doi.org/10.1080/18340806.2014.11082056

Sofronoff, K., Dark, E., \& Stone, V. (2011). Social vulnerability and bullying in children with asperger syndrome. Autism, 15, 355-372. http://dx.doi.org/10.1177/1362361310365070

Sorbring, E., \& Lundin, L. (2012). Mothers' and fathers' insights into teenagers' use of the internet. New Media \& Society, 14, 1181-1197. http://dx.doi.org/10.1177/1461444812440160

Stanford. (2015). Self-efficacy for managing chronic disease 6-item scale. Retrieved from http://patienteducation.stanford.edu/research/secd6.html

Sunderland, N., Chenoweth, L., Matthews, N., \& Ellem, K. (2014). 1000 Voices: Reflective online multimodal narrative inquiry as a research methodology for disability research. Qualitative Social Work, 14, 48-64. http://dx.doi.org/10.1177/1473325014523818

Tajfel, H. (2010). Social identity and intergroup relations: Cambridge University Press.

Turner, J. C., Brown, R. J., \& Tajfel, H. (1979). Social comparison and group interest in ingroup favouritism. European Journal of Social Psychology, 9, 187-204. http://dx.doi.org/10.1002/ejsp.2420090207 
Walker, D.-M. (2013). The internet as a medium for health service research. Part 1. Nurse researcher, 20(4), 18-21. http://dx.doi.org/10.7748/nr2013.03.20.4.18.e294

Wells, M., \& Mitchell, K. J. (2007). Youth sexual exploitation on the Internet: DSM-IV diagnoses and gender differences in co-occurring mental health issues. Child \& Adolescent Social Work Journal, 24, 235-260.

http://dx.doi.org/10.1007/s10560-007-0083-z

Wells, M., \& Mitchell, K. J. (2014). Patterns of Internet use and risk of online victimization for youth with and without disabilities. The Journal of Special Education, 48, 204-213. http://dx.doi.org/10.1177/0022466913479141

WHO. (2014). Global Status Report on Non-Communicable Diseases.

Wiles, R. (2012). What are qualitative research ethics? London \& New York: Bloomsbury Publishing.

Wiles, R., Crow, G., Charles, V., \& Heath, S. (2007). Informed consent and the research process: Following rules or striking balances? Sociological Research Online, 12(2). http://dx.doi.org/10.5153/sro.1208

Yen, C.-F., Chou, W.-J., Liu, T.-L., Ko, C.-H., Yang, P., \& Hu, H.-F. (2014). Cyberbullying among male adolescents with attention-deficit/hyperactivity disorder: Prevalence, correlates, and association with poor mental health status. Research in Developmental Disabilities, 35, 3543-3553. http://dx.doi.org/10.1016/j.ridd.2014.08.035

Zinner, S. H., Conelea, C. A., Glew, G. M., Woods, D. W., \& Budman, C. L. (2012). Peer victimization in youth with Tourette syndrome and other chronic tic disorders. Child Psychiatry And Human Development, 43, 124-136.

http://dx.doi.org/10.1007/s10578-011-0249-y

\section{Correspondence to:}

Dr Zhraa A. Alhaboby

Institute for Health Research (IHR), and the National Centre for Cyberstalking Research (NCCR)

University of Bedfordshire

University Square, Luton

LU1 3JU

United Kingdom

Email: zhraa.alhaboby@beds.ac.uk 


\section{About Authors}

\section{Dr. Zhraa A. Alhaboby}

Zhraa is a qualified medical doctor (MBBS), and MSc in International Primary Healthcare from Barts and the London School of Medicine and Dentistry (QMUL). She has a cross-cultural clinical experience overseas in over 18 hospitals and clinics. In a multidisciplinary team she conducted a Community-Based Participatory Research (CBPR) to evaluate a peer-support programme in East London, she is actively involved in culturally-sensitive health promotion campaigns. She teaches undergraduate and postgraduate modules in the Faculty of Health and Social Sciences. Zhraa is currently researching the impact of cyber-victimisation on people living with chronic conditions at the Institute for Health Research (IHR), University of Bedfordshire.

\section{Prof. Jim Barnes}

Jim is a Chartered Psychologist and an Associate Fellow of the British Psychological Society (BPS). His personal research interests focus on the neuropsychological aspect of cognition, particularly psychosis and deviant behaviours in both clinical patients and the general population. He has been involved in a variety of projects working with individuals with Parkinson's disease, dyslexia, PTSD and more recently has been a member of the National Centre of Cyberstalking Research (NCCR), and is currently working with Bedfordshire PCC and the Home office on a national cyber harassment Police project.

\section{Dr. Hala Evans}

Dr Evans is a senior lecturer in Public Health at the University of Bedfordshire, UK. She leads/teaches two core academic modules for postgraduate students in health studies. Her research interests are focused on four main areas, inequality in health, violence/aggression in schools, communicable diseases and non-communicable diseases and health and lifestyle.

\section{Dr. Emma Short}

Emma is a Chartered Psychologist and Associate Fellow of the British Psychological Society. As Director of the National Centre for Cyberstalking Research she is a researcher in online behaviour, principle investigator of the ECHO project and currently leading a Home Office funded project for Cyberharassment creating a Platform for Evidence Gathering, Assessing Risk \& Managing Policing. The NCCR is a multidisciplinary team investigating the methods, nature and impact of cyberstalking. Emma's research has identified that the impact of sustained online threat which characterises cyberstalking poses significant risk, with many victims reporting clinical levels of PTSD.

Editorial record: First submission received on September 11, 2016. Revision received on February 4, 2017. Accepted for publication on May 5, 2017. The article is part of Special Issue "Internet use and disability - Risks, opportunities and challenges" guest edited by Emma Sorbring and Martin Molin. 